\title{
Is It Necessary a Renewal of the Theory of the Firm Based on Pandemic realities?
}

http://doi.org/10.21272/bel.4(2).96-101.2020

\author{
Alexandru Trifu, ORCID: https://orcid.org/0000-0001-9891-4836 \\ $\mathrm{PhD}$, Professor, Faculty of Economics, Department of Economic Sciences, University "Petre Andrei" of Iasi, \\ Iasi, Romania
}

\begin{abstract}
This paper deals with the study of the reverse impact made by the state regulation of entrepreneurial activity on economic development indicators and with substantiation of the expediency to develop new business management theories. According to the analysis of studies on "firm" definition and the peculiarities of its operation, these issues have been actively studied since Adam Smith when the firm was an important component of the marketplace, and until the legislative definition and certification of its operation. The article considers the firm a legal entity, an open economy institution operating under corporate law. The study is conducted based on a critical review of the literature in this field, including information and news of the pandemic period, the synthesis of which allows to draw conclusions about the possibility and need to update the theoretical basis for organizational management, based on the deduction method. According to the analysis results, today, the firm operates in conditions of increased competition and an open environment. Its main functions are the production of goods or services, making a profit and meeting the needs of the population, government agencies or other firms, and the basis of the activities of legislation and regulations approved by government agencies. One of the main problems in modern firms' functioning is the coronavirus pandemic, which is the essential structural crisis in the economy after World War II. It caused rising unemployment, significant loss of profits, and bankruptcy of small and medium-sized enterprises. Thus, one of the most stable and efficient sectors of the pandemic economy is the IT business and the catering sector. The study shows the need to transform organizations' existing management strategies in terms of their adaptation to the realities of the modern world economic system. The study results can be useful for managers and heads of enterprises in improving the efficiency of firms during the crisis.
\end{abstract}

Keywords: Lockdown, Pandemic, Profit, Public Authorities Support, Theory of the Firm, Wellbeing.

JEL Classification: D21, E71, M38.

This work is licensed under a Creative Commons Attribution 4.0 International License

Cite as: Trifu, A. (2020). Is It Necessary a Renewal of the Theory of the Firm Based on Pandemic realities? Business Ethics and Leadership, 4(2), 96-101. http://doi.org/10.21272/bel.4(2).96-101.2020.

(C) The Author, 2020. This article is published with open access at Sumy State University.

\section{Introduction}

The problem to be analyzed in the following rows started from the general concept of Management which surrounds us in every respect of our lives and activities. Browsing the literature in the field and, at the same time, the feedback coming from the practice, taking into account the unexpected and even invisible challenges, we agree that for now and for medium-run, the knowledge, abilities, skills, specific psychological traits as positive thinking and empathy, humans will remain the most adequate and functional beings to manage [18].

Developing and adapting these theories of management, entrepreneurship, or leadership to the new realities and challenges, it is possible and we are saying, even mandatory, to find new theoretical approaches, capable to fix these realities and to lead to functional strategic framework of management and of the other components. The basic approaches remain, including the decisive action of decision-making, both in SMEs and TNCs (Hebert at al., 2009; Zimmerer et al., 2008).

The pandemic came and alters the structural relationships, especially when it's about strategic management and development (Barney et al., 2006). That is even the theoretical construction of management theories, these ones pliable to the best applications for the workforce and company's culture, based on knowledge and skills (Grant, 1996). 
We are living in times when the authorities and public sector (administration and, especially, health care system) are in charge in determining measures, in the form of state of emergency, or of a state of alert, to manage the people lives and social-economic activities. Economies and societies/groups are stick together and, of course, policies are needed to be issued for all domains of activities, for both public and private sectors. These new realities, the necessity of problem-solving, even life and death, involve a rethinking of what to do to meet the urgent demands, but also demands to spin the economic life.

\section{Exposure of the Issue}

The literature in this important domain of our lives and economic activities, that is the complex Theory of the Firm, is very large and diverse, starting around 1930s with the work of Ronald Coase (1937), laureate of the 1991 Nobel Prize in Economic Sciences. In this paper, we are interested in recent achievements in the field, particularly, regarding psychological aspects as well as the relationships between entrepreneurs/CEOs/managers and employees/workers that ensure the well-functioning of the firm and sustainability on its specific market (Sautet, 2006).

Peter Klein (2016) is one interesting author in what we intend to highlight, because he successfully and to a large extent included the theory of the entrepreneurs into the main theoretical ground of the Theory of the Firm and, at the same time, emphasized the specific influence of the particularities of the theory of entrepreneurs on a better understanding of the multidimensional corpus of the Theory of the Firm (Klein, 2016). Also, the work of P. Aghion, Dewatripont, Legros, Zingales (2016) is an attempt to refine the existing theory and it is, also, an example for the increasing use of the language and style of contemporary formal economics (that is activities embedded in a legal framework, with continuous relationships between public authorities and the other economic and social actors).

Paraphrasing a well-known scientific title, we can say that entrepreneurs/CEOs need firms (small, medium, corporate) and, vice versa, firms need good managing theories and decisions. The lockdown was the main sanitary decision to curb the spread of the new coronavirus, and the new modality of working from home, where it was possible, was successfully used in order to maintain the safety of employees and, at the same time, to not hamper the output and to sustain the business activity.

The entrepreneurs (from the French word entrepreneur for a person who engages in a business) are considered even a factor of production within a standard economic system (along with land, workforce, capital). In fact, we may consider them along with CEOs and managers as "propellers" for the economic system, the main human resource for the existence of economic and social activities. In the present situation, we are interested in the ways of re-establishing economic life and in the modalities of managing entities/organizations after the obvious huge slowing down of all social and economic activities. Therefore, we looked for some appropriate organization managing theories and theories of entrepreneurship that relate to the scope of the present paper. In this respect, we have chosen theories $\mathrm{X}, \mathrm{Y}$, and $\mathrm{Z}$ and, on the other hand, the Cochran and Kirzner theories of entrepreneurship.

Theory X, Y was stated and sustained by Douglas McGregor (2006), a management professor at MIT. In his capital work of 1960, The Human Side of Enterprise, the author focused on how managers/CEOs perceive and address employee's motivation, under the form of two manifestations: Theory $X$ and Theory $Y$.

The first one (X) assumes that the monetary factor is paramount for employee motivation and, we may say, the support for pursuing happiness. This aspect is doubled by the security need, as in the basic needs level of the Maslow Pyramid of Needs (McLeod, 2020): 


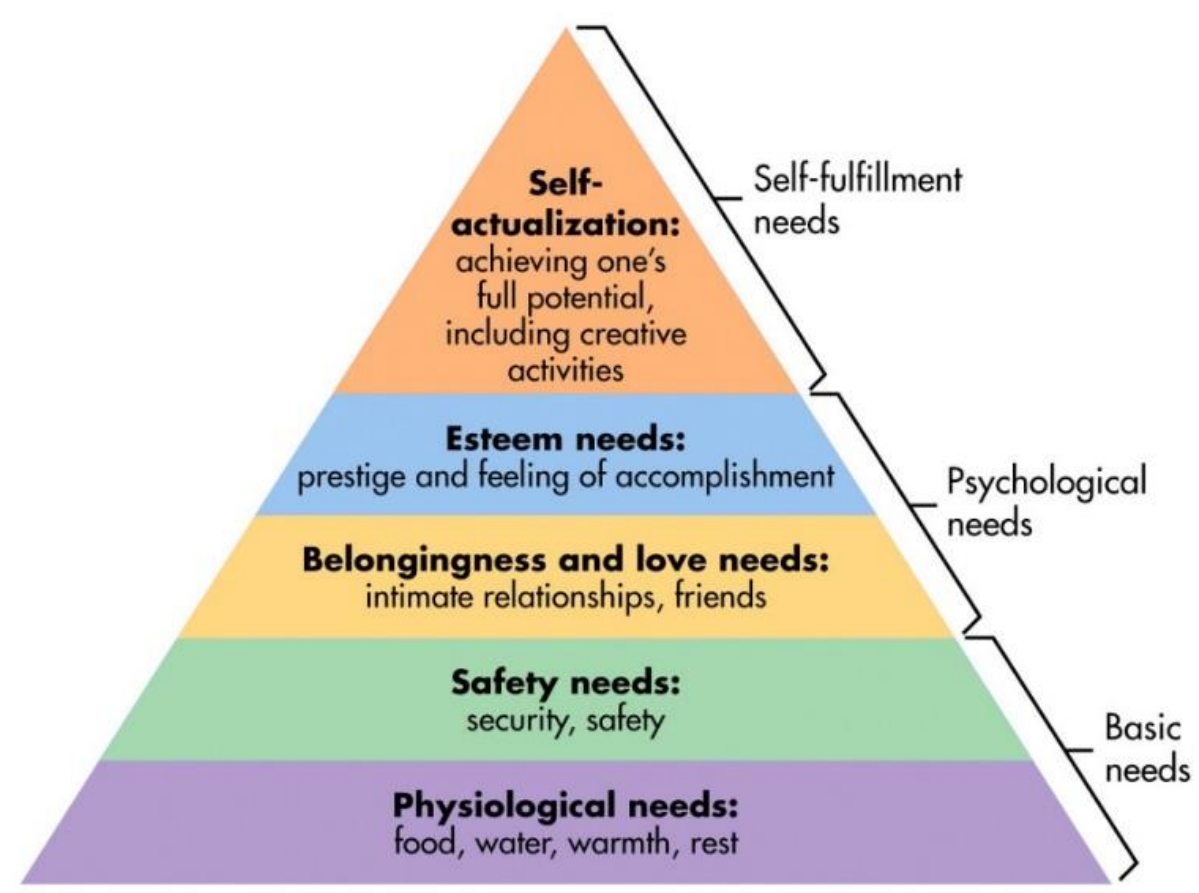

Source: McLeod, 2020

Figure 1. Maslow Pyramid of Needs

Theory $Y$ assumes that it is an authentic possibility to align personal goals and organization goals, with people/employees being considered creative and participative to the organization actions, and with the esteem and self-actualization levels (Figure 1) being seen as ongoing needs for people, but never completely satisfied.

Theory $Z$, on the other hand, stresses the need/intention to help workers to become somehow generalists in their domain of expertise, rather than specialists. It was introduced by management professor Ouchi (1993) who presented some assumptions about employees, such as: developing co-operative relationships with coworkers, i.e. an imperative desire for affiliation, and that workers expect reciprocity and support from the company. This the aspect that we want to highlight working people seek support from their firm to secure and maintain a balance between work and personal life, in the latter being included family, culture, habits and even the pursuit of happiness. As professor Ouchi said, and other authors appreciated, Theory $Z$ is not the last word in relational management, but it seems to be a right support to it, which can be beneficial in cases as in the period we are going through. In the essence, Theory $Z$ allows to develop, among others by rotation and training of the employees, a more dedicated, loyal and permanent workforce, which benefits most of the companies. And it is exactly these employees/people, on which the management of the companies can rely for reestablishing the business and for the re-use of the workforce temporary sent into technical unemployment [20]. Regarding the two Theories of entrepreneurship, we consider them pliable on what has happened in this period and conducive to re-building the theoretical framework in the field.

The Cochran Theory, or the cultural theory of entrepreneurship, is a sociological approach of this issue. Cochran (1965) considers the entrepreneurs as an emerging personality of society. The dynamics in the activity of an entrepreneur is depending on social factors, which result from changes and actions of the business and the business environment. The theory looks at the culturally determined inter-connection between the potential and the attitude of entrepreneurs with the expectations by the sanctioning groups, i.e. by those who facilitate new entrepreneurial ventures. Enlarging the significance of Cochran Theory, we consider the role of entrepreneurs defined by those groups, i.e. members of board of directors, other top officials and, further, by the groups with which the owner/entrepreneur interacts closely within the firm/corporation, in achieving the proposed goals.

The Kirzner theory $(1973 ; 2009)$, called The Alertness Theory of Entrepreneurship, is based on the idea of spontaneous learning and which is perfectly adaptable to the actual situation, like in the "Crusoe example". The rationale is that the entrepreneurs/CEOs/managers must promptly respond to the challenges and changes produced in short-term within economy and society. In a word, both owners and decision-makers must stay alert and monitor the development of facts and phenomena and the regulations issued by executive and legislative powers [19]. 


\section{Methodology}

The approach of the literature review in this field, along with the information and news from the pandemic period, were the basic elements of this paper's scientific construction. The synthesis of all these elements led to the issuance of our own opinion, through deduction method, regarding the possibility and the necessity of renewing the theory on the matter of organization management.

The ongoing process of checking realities on which to base a renewal of the theory. The realities during the pandemic time, with priority on a decisive policy of lockdown, have shown that for ensuring the general restart of economies, for the elimination of technical unemployment and for diminishing the general unemployment level it is mandatory that economic and social activities return to a reasonable intensity. What we saw that thee cities were silent; the quasi-majority of businesses were closed because the lockdown was the main measure taken by the authorities in order to stop the spread out of the new coronavirus. The healthcare was the priority, but, at the same rank, it was necessary to envisage solutions to stop the failing down of the economies because anyone felt that the pandemic was and is still bad for economy and society. So, what we also see is that the European Union is prepared to support the member states' economies with a huge recovery fund of more than 540 billion euros, under the German and French initiative, in a so-called "Hamilton momentagreement" ${ }^{1}$ between the wealthiest and most powerful countries of the EU. This is meant to be a breakthrough moment in the lockdown situation of entire Europe (McCaffrey, 2020).

Under the German and French initiative, the European Union has managed a concrete solution, but there are other solutions to come up which will use the general EU budget to transfer money to those countries or regions that need it most. In this respect, the management of European Commission has drafted a plan of more than a trillion Euros to support economies (with the main focus on technical unemployment) towards a gradual reopening of Europe that will provide goods and services to its citizens again and, finally, produce profit (some see this as the pressure of the business sector on political decision-makers - but without profit there is no investment and without investment there are no goods and services). Furthermore, one month ago, the leaders of EU signed off more than 500 billion euros fund to keep people in work and businesses afloat (our emphasis). The logic and reasonable solution was to pump and transfer money, as quickly as possible, and which might even amount to a package of 2.4 trillion euros, for the economies or parts of Europe that needed it most, either under the form of grants, or under the form of loans.

So, in this period, we experience (or we expect to experience) the impact of regulations from EU institutions and/or national authorities to the social and economic environment. These solutions are designed for the entrepreneurs who desperately intend to re-open the businesses and for employees and customers that will reestablish the supply-demand game on the market, in the benefit of all parts involved in. The initial question asked by the European authorities was "Sink or Swim"? The answer is clear: all member states need to act as one, either sink together, or float/swim together (McCaffrey, 2020). On the one side there are the public authorities with support funds, on the other there are the abilities, skills, knowledge of entrepreneurs, CEOs/managers, who comprehend how to use those funds for achieving their goals, for re-starting their activities and for ensuring a reasonable level of revenues and wellbeing of employees and people in general.

The nexus to abilities, skills and knowledge is another part of the ongoing research on entrepreneurship and the theory of the firm. It can be categorized into several taxonomies or theoretical sequences, that have come up in the last 5-6 years (McMullen, 2015; McCaffrey, M., 2015 and others). They focus on the two positive parts of a SWOT analysis, Strengths and Opportunity, along with Alertness on possible internal and external disturbance-factors and on the Judgment approach in selecting, monitoring and co-ordination of all assets and human resources or, in multi-person firms, the delegation of decision authority to other owners or employees. It is these categories that serve best for the renewal of the theory of the firm.

And we have a clear connection to praxis: The necessity for new ideas and sequential theories, is mirrored in a forecast of the International Labour Organization, indicating that approx.195 million jobs will be lost around the world in the next three months (McCaffrey, 2020). In order to understand the Conclusions, we consider that the aspect proves that the coronavirus crisis is more devastating on employment than the global recession ten years ago. It remains to be seen whether the instruments provided by the E.U. will make this loss of jobs a temporary one. But, as said, the financial instruments provided must be complemented by the entrepreneurial

${ }^{1}$ The term was used to show the parallel with the legendary fiscal union forged by U.S. treasury secretary Alexander Hamilton after the American Revolution that helped prevent states from being bankrupted by their war debts. 
resources exhibited above and of which we think that they must be embedded into a renewed theory of the firm.

The practice in Economics is developing faster than the theories, especially that is necessary de recover the losses in these last three months and new modalities of chain distribution, new instruments for delivery (such as drones), automated deliveries companies, especially Chinese e-commerce and others, prove that we cannot speak about the end of Economics, but rather that the thinking in this domain to become a sound support for these realities and necessities. Our lives have changed, but we must know how to manage the medical danger and to succeed a desired level of satisfaction, even happiness.

\section{Conclusions}

In general, the theory of the firm includes entrepreneurial concepts and concepts of organization management. Its value for practice lies with being adaptive and with prompting responses to all influences or changes, and with ensuring innovative actions as well as the proper functioning of all components, actors and factors involved in entrepreneurial and management activities.

Regarding the impact of the new coronavirus, it is obvious that it has changed and is changing all around us, all of our known world, but not at the same time and not to the same extent. It is essential to develop a quick answer to the coronavirus challenge and to its effects on other environmental factors in order to preserve the health of people and maintain the due course of society. A major contribution comes from innovative thinking, swift and smart decisions, training the employees/workers to perform activities that will re-establish the functioning of the firms and, step by step, the growth of their revenues and welfare.

We think that the modality of a tryptic action type which includes alertness-innovation-smart decisions will help to understand the functional internal environment and provide quick responses and adaptations to external factors and regulations. For praxis, this is the way to efficient action; for scholarly purposes it has to be transposed into a flexible sequence that can be embedded into the Theory of the Firm, as a whole.

These findings impact also on higher education institutions, which are involved, more or less explicitly, in relationships of students that are similar to those between CEOs/decision-makers and other persons., Students should be supplied with solid knowledge, but especially with abilities and skills to understand facts that surround them, to respond quickly and to operate efficiently and effectively within an entity/firm/organization.

\section{References}

1. Aghion, P. et al. (eds.). (2016). The impact of incomplete contracts on economics, New York: Oxford University Press. Available at: www.global.oup.com.

2. Barney, J. B. \& Hesterly, W. S. (2006). Strategic management and competitive advantage: Concepts and cases, Upper Saddle River, NJ: Pearson/Prentice Hall. Available at: www.theacademicessays.com.

3. Bylund, Per. (2018). The Economic Theory of the Firm, accessed June 9, 2020. Available at: www.mises.org/library/.

4. Coase, R. (first published 1937). The Nature of the Firm, in Economica, 4(16), 386-405. Accessed May 15, 2020. Available at: www.onlinelibrary.wiley.com.

5. Cochran, T. C. (1965). The entrepreneur in economic change, Explorations in Economic History, 3(1), $25-38$. Available at: www.entrepreneurshiptheories.blogspot.com.

6. Grant, Robert M. (1996). Toward a Knowledge-Based Theory of the Firm, accessed June 5, 2020, Available at: www.researchgate.net/publication/.

7. Hebert, R. F. \& Link, A. N. (2009). A history of entrepreneurship, New York: Routledge. Available at: www.1lib.eu/book.

8. Kirzner, Israel M. (2009). Competition and Entrepreneurship, abstract on www.papers.ssrn.com accessed May 20, 2020, paper written 1973.

9. Klein, Peter G. (2016). Why entrepreneurs need firms and the theory of the firm needs entrepreneurship theory. Revista de Administração, 51, 323-326, accessed May 5, 2020. Available at: www.sciencedirect.com.

10.Klein, Peter G. (2016). My contributions to entrepreneurship theory, in Audretsch \& Lehman (eds.) The Routledge companion to the makers of modern entrepreneurship, Routledge. Available at: www.mises.org/wire/.

11.McCaffrey, D. (2020). Coronavirus Briefings, months of April and May, www.euronews.com accessed May 3 and June 1st, 2020. 
12.McCaffrey, M. (2015). Economic policy and entrepreneurship alertness or judgement? In P.L. Bilund \& M. McCaffrey (eds). The next generation of Austrian Economics. Essays in honor of Joseph T. Salerno, 183-199. Available at: www.papers.ssrn.com.

13.McGregor, D. (2006). The Human Side of Enterprise, Bew York:McGraw-Hill Companies, Inc. Available at: www.amazon.com.

14.McLeod, S. (2020). Maslow's Hierarchy of Needs, accessed May 10, 2020. Available at: www.simplypsychology.org.

15.McMullen, J. S. (2015) Entrepreneurial judgment as empathic accuracy: A sequential decision-making approach to entrepreneurial action. Journal of Institutional Economics, 11(3), 651-681. Available at: www.cambridge.org/core/.

16.Sautet, F. (2006). An Entrepreneurial Theory of the Firm, Foundations of the Market Economy, published by Routledge, New York. Available at: www.amazon.com.

17.Zimmerer, T. W. \& Scarborough, N. M. (2008). Essentials of entrepreneurship and small business management, Upper Saddle River, NJ: Pearson/Prentice Hall. Available at: www.pearson.com/us/.

18.***Management theories. Concepts surrounding recommended management strategies, www.corporatefinanceinstitute.com/resources/, accessed June 10, 2020.

19. ***Top 14 Theories of Entrepreneurship (with Criticism),www.businessmanagementideas.com. Accessed May 18, 2020.

20. ***Reading: Ouchi's Theory Z, Introduction in Business, accessed May 18, 2020, Available at: www.courses.lumenlearning.com. 